\title{
BUILDING A BUSISESS PROCESS MANAGEMENT CENTER OF EXCELLENCE
}

\begin{abstract}
Business Process Management has risen in attractiveness for organizations as a holistic management practice dedicated to enabling and sustaining corporate success. Business Process Management centers of excellence are growing in popularity as many organizations An increasing number of companies adapting a business process centers of excellence, which is a center for process improvement and provides many good practice solutions. These solutions are the basics for improvements of process-oriented enterprises. The aim of this article is to present the building of Business Process Management centers of excellence in contemporary enterprises.
\end{abstract}

Keywords: process, Business Process Management, Business Process Management Center of Excelence

\section{Introduction}

Business Process Management (BPM) has become more and more attractive for organizations as a holistic concept practice dedicated to enabling and sustaining corporate success. The enterprise-wide adoption of Business Process Management in organizations typically goes through multiple stages (ROSEMANN M. 2009). An awareness of the benefits and methodologies of Business Process Management has to occur. this awareness and understanding of BPM has to convert into a desire to adopt. Assuming the business case was successful, individual BPM projects have to be set up, executed, and monitored, often with the desire to achieve quick win situations that can then be used to market and expand the BPM ideas across an organization. assuming that individual BPM projects have been successful, organizations seek a wider capitalization on the BPM idea and convert from multiple BPM projects to a governing and typically more centralized BPM program (JESUS L., et. al 2009).

In selected companies that have implemented process management, there are Business Process Management Center of Excelence (called as Business Process Management Support Office, Process Improvement Centers. These units are an important organizational mechanism that has been adopted by companies seeking to institutionalize process management initiatives. The process management office is

\footnotetext{
${ }^{1}$ Prof. nadzw. dr hab. inż., Wyższa Szkoła Finansów i Zarządzania w Warszawie, e-mail: pbab@wp.pl - 163 -
} 
a centralized unit whose main task is to introduce good practices and process management.

The activity-focused view of such a maturity-driven BPM roadmap, it is now required to productize BPM, i.e., to consciously identify the BPM-related services offered by such a BPM Group. Centers of excellence is, a cross-functional body that brings together a group of people to focus on a single process area, business activity, or capability.

A BPM Center of Excellence (BPM CoE) is a governance mechanism that is widely adopted by organizations aiming for a consistent and centralized roll-out of BPM initiatives (JESUs L., et. al 2009) .

Business Process Management Center of Excelence (BPM CoE) concept suggests several dimensions that appear particularly salient. tend to have a physical presence, i.e., they are typically based in a particular organizational subunit. It represent a focus for a superior set of capabilities within the firm, including tangible resources such as equipment, licenses, and patents, and intangible resources such as knowledge and experience.

It is creating value rather than in terms of a specific product or line of business, especially given that many centers of excellence possess fungible capabilities, i.e., capabilities that are able to create value for more than one line of business (e.g., ITT's information technology centers).

\section{Essence of building a Business Proces Management Center of Excellence}

Business Process Management Centers of Excellence are growing in popularity as many organizations begin to expand departmental initiatives to encompass the enterprise. Centers of Excellence are most appropriate for organizations looking to deploy three or more processes that will need to interact with multiple departments. Services can be influenced through appropriate marketing and communication strategies. These capabilities reflect the accumulated knowledge, skills, and experience of the BPM group as well as available technological capacities to successfully deliver the individual service.

Business Process Management Centers of Excellence help to improve service delivery quality by encouraging and providing the mechanism for sharing knowledge, documentation, processes and procedures, data, resources, experience, and best practices across an organization. Business Process Management Centers of Excellence can help an organization develop strategic capabilities by fostering the intake of new knowledge and the sharing of that knowledge enterprise-wide, by bringing together a diverse collection of subject matter experts from different functional areas to work 
together, and by elevating the capability they are organized around from a collection of local, siloed, ad hoc efforts, to a coordinated, enterprise-level, strategic one.

Office can contribute significantly to an employee retention strategy. They bring together employees from around the organization across functional, reporting, and geographic lines, providing the opportunity for employees from different levels to work together closely on a range of initiatives. They also provide the organization a way to discover and nurture talented employees.

Business Process Management Centers of Excellence collects the knowledge and process experience that goes to the knowledge base. One of the most common issues in process knowledge is the experience and conclusions accumulated by the process team, and also collected in process models. It can be defined as new knowledge, experience, and insights into the areas of its implementation. This allows continually improve and benefit from the organizational, team, or individual knowledge you have created. Preserving process knowledge allows organizations to learn in shorten time and reduce costs of accessing knowledge and consequently, to process processes and work better.

It makes possibility to create linkages between and across functions, geographical areas, and reporting hierarchies. Business Process Management Centers of Excellence can help improve the IT engagement model and the problems related to it first by shifting the ownership of the IT engagement model. It provides a framework of policies, procedures, and processes that supports improved interactions between all stakeholders precisely because it's coming from a cross-functional, enterprise perspective, rather than just the IT perspective. A Business Process Management Centers of Excellence can help IT rationalize delivery timelines in a number of ways to improve the IT engagement model, which plays a big part in delivery timelines. From the first point of contact with a business customer to the release of an application to production, every step of the engagement model can be retooled to improve service delivery and customer satisfaction.

\section{Services of Business Process Management Center of Excellence}

Process management offices primarily deal with support and management tasks in process management. The most important functions of project management offices are (Roseman M. 2010; Richardson C. 2006, von Rosing M., Hove M., voN SCHEEL H. 2015): 1. Implementation of standards, process management methodologies, 2. Initiating and modeling processes, 3. Coordinate the implementation of processes, 4. Monitoring and controlling processes, 5. Improvement of processes. 
In addition, within the scope of its tasks, the office assesses the maturity of the process, verifies the process's compliance with the company's strategy and mission. In addition, it manages process change management and process improvement, IT support, process change management, and process management (JESUS L., MACIEIRA A., Karrer D., Rosemann M 2009, Frost T.S., Birkinshaw J.M., Esign P.C. 2002).

BPM Centers of Excellence are usually chartered to accomplish the following objectives (ROSEMANN M. 2009, ClAY 2006):

- Prioritize and Implement Processes - The Center of Excellence works with the executive sponsor and business managers to identify and prioritize process projects. As previously mentioned, process selection guidelines should be developed to help the BPM Center of Excellence rank the processes to be implemented. After processes have been prioritized, the Center of Excellence can focus on its primary objective: developing and deploying processes.

- Maintain the Process Library - This consists of maintaining knowledge and documentation captured for each process. This knowledge is often contained in process requirements documents, training manuals, and project plans. The Center of Excellence is tasked with maintaining these artifacts in a physical library or within a virtual knowledgebase.

- Establish Process Best Practices - Upon completion of each deployment, the BPM Center of Excellence conducts post-project reviews and identifies lessons learned. These reviews are used to establish best practices that can be applied to future process implementations.

- Evaluate Process Performance - Working with the process steward and executive sponsor, the Center of Excellence periodically evaluates the effectiveness of deployed processes. Process effectiveness is evaluated based on key performance metrics established prior to process deployment.

The BPM Center of Excellence should be assigned responsibility for defining and enforcing process governance rules. Once process governance rules have been established, these rules should be institutionalized and automated by the Center of Excellence.

The group is a type of internal consulting operation that is responsible for selling BPM and Business Architecture concepts and benefits to the business, building and enforcing standards and common approaches/technique use and a common approach to rules definition and cross group collaboration. The BPM CoE staff is responsible for acting as a coordinator between the business, manufacturing/production and IT to help ensure a holistic view of change. 


\section{Framework of Business Proces Management Center of Excellence}

The framework for the Operation of a BPM Center of Excellence can be devide into five main components: management processes; support processes; main services; complementary services; BPM technologies (Table 1).

Table 1. Characteristic of framework of Business Proces Management Center of Excellence

\begin{tabular}{|l|l|}
\hline Components & Characteristic \\
\hline Processes & $\begin{array}{l}\text { The set of processes related to the management of a BPM Center of } \\
\text { Excellence's internal activities. It includes the translation of strategic and } \\
\text { operational demands into BPM services; the analysis, configuration, and } \\
\text { monitoring of BPM services; the evaluation of results generated by BPM } \\
\text { services; and the communication and dissemination of BPM culture } \\
\text { throughout the organization. }\end{array}$ \\
\hline Support Processes: & $\begin{array}{l}\text { The set of processes that supports the operation of the Center of Excellence. } \\
\text { It includes the creation and maintenance of methods for all activities within } \\
\text { the process lifecycle - establishment of BPM related roles and } \\
\text { responsibilities, administration of the BPM services portfolio, administration } \\
\text { of BPM human resources, charging, and funding. }\end{array}$ \\
\hline Main Services & $\begin{array}{l}\text { These services are central to the implementation of the BPM approach and } \\
\text { are the usual responsibilities of a BPM Center of Excellence1 . This set } \\
\text { includes services like process modeling, process improvement and design, } \\
\text { process change management, process performance management, and process } \\
\text { management education/training. }\end{array}$ \\
\hline $\begin{array}{l}\text { Complementary } \\
\text { Services }\end{array}$ & $\begin{array}{l}\text { Services that may not be the direct responsibilities of a BPM Center of } \\
\text { Excellence, but are still related to the BPM discipline and its methods and } \\
\text { tools. This set of services includes, for example, process auditing, risk and } \\
\text { internal control management, process forensics, systems design. }\end{array}$ \\
\hline BPM Technologies & $\begin{array}{l}\text { The set of systems and technological aspects that support the } \\
\text { implementation of BPM concepts. It captures a high variety of process- } \\
\text { aware information systems, including SOA, workflow management. }\end{array}$ \\
\hline
\end{tabular}

Source: based on ROSEMMAN M. 2009

The framework for the operation of a BPM Center of can help managers in charge of the BPM adoption to consolidate and structure their BPM services and internal processes. This framework is designed to be a starting point for the creation of a BPM Center of Excellence inside an organization, or as a benchmark for the continuous improvement of an existing one. It goes beyond the previously proposed set of BPM services by grouping them and positioning them in a three stage capability model.

\section{Conclusions}

The dynamic increase in the number of processes involved in dealing with intellectual capital and knowledge management is a challenge for modern businesses.

$$
-167-
$$


The growing interest of managers in setting up process management offices and the insufficient number of studies and the lack of Polish literature in this area indicate the need for further scientific and research discussion. Improve process organization with the support of the discussed solutions, based on good practices and recommendations, setting the best ways to achieve the target. Although it needs to be empirically validated in future research, and the final allocation of services to capability levels might still be revised over time, we are confident that this structure provides a valuable reference point that captures the important dimensions of a BPM Center of Excelence.

\section{Bilbligraphy}

1. Frost T. S., BIRKInshaw J.M., ENSIGN P.C. 2002. Centers of excellence in multinational corporations. Strategic Management Journal”, Vol. 23, Issue: 1, pp.997-1018.

2. Jesus L., Macieira A., KARRer D., Rosemann M. 2009. A Framework for a BPM Center of Excellence. http://www.bptrends.com/bpt/wp-content/publicationfiles/FOUR\%2009-09ART-Framework\%20for\%20BPM\%20Ctr\%20Excellence-Jesus\%20et\%20al.pdf, data dostępu 25.05.2017r.

3. Harmon P., Wolf C. 2012. Business process Centers of Excellence Survey. Business Process Trends.com, http://www.bptrends.com/bpt/wp-content/surveys/2012-BPTrendsCoE-Survey-3.pdf, data dostępu 16.04.2017r.

4. Ko R.K.L., LEE S. S.G., LEE E.W. 2009. Business process management (BPM) standards: a survey. "Business Process Management Journal", Vol. 15, No. 5.

5. NADARAJAh D., LATIFAH S., KADIR S. A. 2016. Measuring Business Process Management using business process orientation and process improvement initiatives. "Business Process Management Journal”, Vol. 22, Iss: 6, p. 1069-1078.

6. Rosemann M. 2010. The Service Portfolio of a BPM Center of Excellence. Handbook on Business Process Management, Springer Berlin Heidelberg, p. 267-284.

7. Richardson C. 2006. Process Governance Best Practices: Building a BPM Center of Excellence, "Business Process Trends", http://www.bptrends.com/publicationfiles/09-06ART-ProcessGovernanceBestPractices-Richardson.pdf , data dostępu 10.04.2017 r.

8. von Rosing M., Hove M., von Scheel H. 2015. BPM Center of Excellence. The Complete Business Process Handbook, p. 217-239.

9. Building the Foundations for a BPM CoE.

10. http://www.processexcellencenetwork.com/business-process-management-

bpm/columns/how-do-you-know-if-you-need-a-bpm-center-of-excell/, data dostępu 17.05.2017 r. 